\title{
Global change implications on long-term water supply and demand forecasts in the Columbia River Basin
}

\author{
M. Barber ${ }^{1,2}$, J. Adam ${ }^{2}$, M. Brady ${ }^{3}$, K. Chinnayakanahalli ${ }^{1}$, \\ K. Rajagopalan ${ }^{2}$, S. Dinesh ${ }^{2}$, C. Kruger ${ }^{4}$, C. Stockle ${ }^{5}$ \& G. Yorgey ${ }^{6}$ \\ ${ }^{1}$ State of Washington Water Research Center, \\ Washington State University, USA \\ ${ }^{2}$ Civil and Environmental Engineering, \\ Washington State University, USA \\ ${ }^{3}$ School of Economic Sciences, Washington State University, USA \\ ${ }^{4}$ Center for Sustaining Agriculture and Natural Resources, \\ Washington State University, USA \\ ${ }^{5}$ Biological Systems Engineering, Washington State University, USA \\ ${ }^{6}$ Center for Sustaining Agriculture and Natural Resources, \\ Washington State University, USA
}

\begin{abstract}
The Columbia River Basin (CRB) encompasses parts of seven US states and British Columbia in Canada over a land mass approximately the size of France.It is a vital part of the ecosystem and economies of the entire region. The CRB, like many watersheds around the world, is experiencing increased pressure on water resources and ecosystems, due to population growth, threatened and endangered species, economic development, and climate change. Irrigation is responsible for the majority of consumptive use in the watershed so the implications of climate change are a tremendous concern as we strive to feed a growing population. To facilitate strategic planning and investment, the State of Washington requires a long-term water supply and demand forecast (the Forecast) every five years. An interdisciplinary WSU research team integrated three biophysical models with an agricultural economics model to conduct a system-wide assessment of how future environmental and economic conditions are likely to change water supply and demand by 2030. Timing of supply changes will shift water away from the
\end{abstract}


times when demands are highest. Unregulated surface water supply at the mouth of the watershed will decrease an average of $14.3 \%$ between June and October, and increase an average of $17.5 \%$ between November and May. The model predicts an additional 141,000 acre-feet $(17.3 \mathrm{MCM})$ of water will be required just to maintain existing irrigation in Washington. The average gross revenue per acre for irrigated land in Washington was estimated to be $\$ 3,500$ and average water use is 3.1 acre feet per acre. Applying these two values to the 141,000 acre foot shortage translates into a decrease in value of production of $\$ 159$ million per year although actual losses would likely be less as farmers could reduce water demand by favoring less water intensive crops such as wine grapes or chose to reduce production of lower value irrigated crops first. Within the entire CRB, an estimated 298,500 acre-feet of additional water will be needed. Localized impacts could be more severe than the broader overall averages. The Forecast will help the State of Washington's Office of Columbia River strategically fund water supply projects by improving understanding of where additional water supply is most critically needed, now and in the future.

Keywords: sustainable agriculture, hydropower, watershed planning, economic development, climate change.

\section{Introduction}

The 250,000 square mile Columbia River Basin (CRB) encompasses parts of seven US states and one province in Canada (see Figure 1). The river is vital to the social, cultural, and economic well-being of the region, providing water supplies for agricultural, industrial, municipal, recreational, and ecosystem uses as well as low-cost hydropower. The river and its tributaries irrigate 7.8 million acres of farmland and generate an annual average of more than 16,600 megawatts of electricity in the US and Canada. Managing water resources effectively and equitably among competing interests across the multitude of jurisdictional boundaries continues to represent a tremendous challenge for decision makers despite decades of collaborative efforts. Severe flooding and a growing need for hydropower prompted the US and Canada to ratify a Columbia River Treaty in 1964 that permitted construction of three large storage projects in Canada (Duncan, Keenleyside, and Mica) and one in the US (Libby), resulting in improved water management; yet, challenges still remain. Beneficial uses beyond flood control and hydropower are becoming increasingly important as water managers strive to protect aquatic species and provide water for growth. Variations in water demand and the overshadowing effects of changing climate and growing population will require modifications of river operations in the $21^{\text {st }}$ century. As competition for scarce water resources increases, more conflict is expected between neighboring states as well as US-Canada interests. Future water management decisions involving the complex interactions and trade-offs between finite water supplies and growing societal demands should be based on sound transdisciplinary science communicated to multiple audiences. 


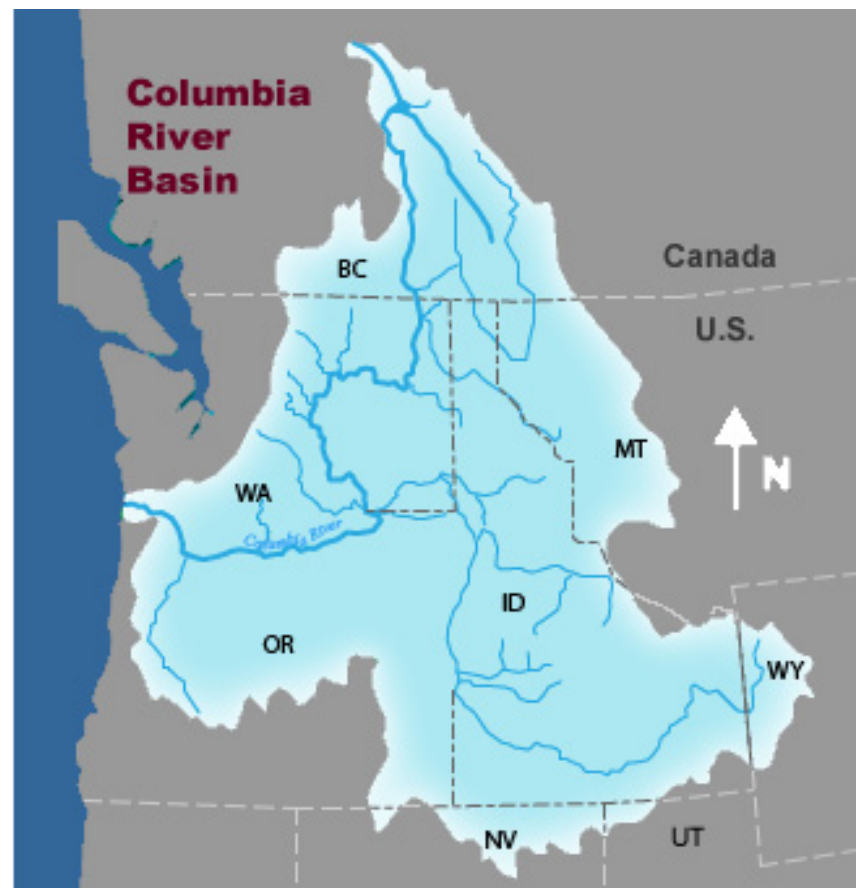

Figure 1: $\quad$ Schematic of Columbia River system.

Recognizing that development of new water supplies for eastern Washington is a priority, Chapter $90.90 \mathrm{RCW}$ directed the Washington State Department of Ecology (Ecology) to aggressively develop water supplies for instream and outof-stream uses specifically for: 1) permitting new water rights; 2) securing water for drought relief; 3) providing water for instream flows to benefit fish; and 4) addressing aquifer decline in the Odessa Subarea by replacing groundwater sources with surface water sources. Working with Ecology's Office of Columbia River (OCR), WSU researchers developed the interdisciplinary framework and tools necessary to project future water supplies and demands based on economic and social impacts and thus allow strategic investments in water infrastructure that will promote job creation while protecting the environment for future generations.

\section{Innovative modeling framework}

To determine the potential impacts of climate variability on future water supply and demand scenarios across the CRB, the WSU research team integrated three existing biophysical models with an agricultural economics model. The result of this integration was a sophisticated water resources modeling system capable of producing a long-term Columbia River surface water supply and demand forecast encompassing municipal, agricultural, hydropower, and ecosystem 
concerns. The model includes the following elements: 1) integration of a largescale hydrologic model (VIC) with a cropping system model (CropSyst); 2) inclusion of water management through reservoir and water rights curtailment modeling (ColSim); and 3) interactions with economic modeling to explore feedbacks from human response to climate change and the global economic environment (see Figure 2).

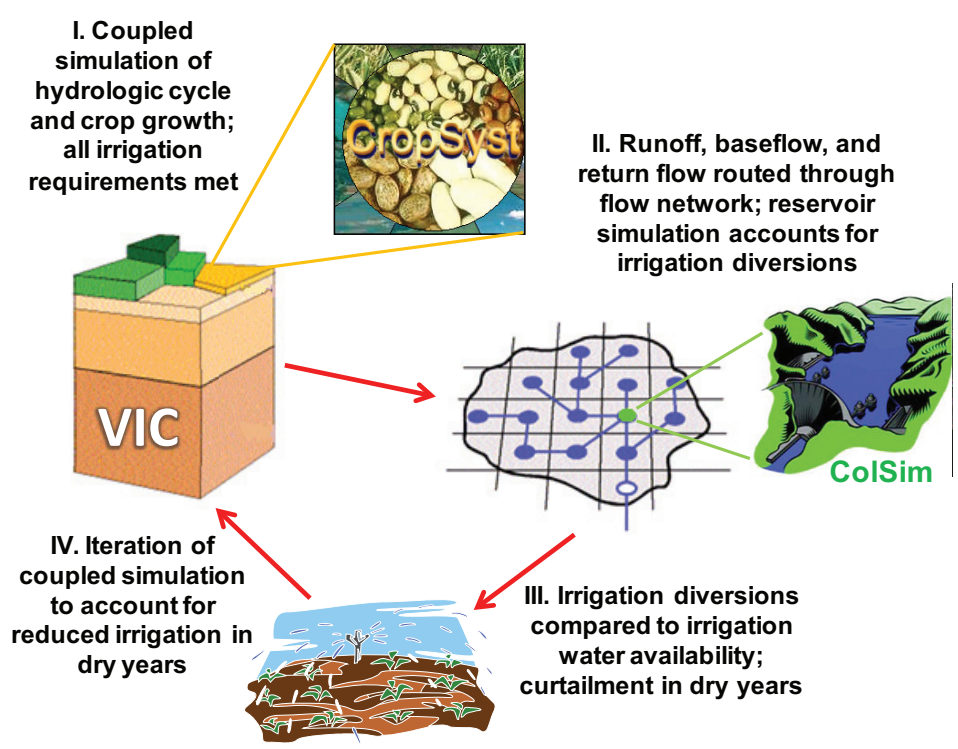

Figure 2: Integrated modeling framework involving VIC, CropSyst, and ColSim.

VIC, CropSyst, and ColSim have been used independently many times to simulate conditions in the CRB. WSU's novel approach is that the VIC and CropSyst models were integrated to exchange hydrologic and crop production information, using daily precipitation and temperature observations from across the basin for 1977-2006 to generate baseline simulations of present water and crop conditions. To forecast future conditions, the model used daily weather information for the 2030s decade from five different climate change scenarios, representing a range of future greenhouse gas emissions and adapted for our region by the Climate Impacts Group at the University of Washington. Using supply and demand information, ColSim routed water through the system looking at adopted instream flow requirements and curtailment rules provided by the OCR. By combining water availability with short-term and long-term economic forecasts related to crop pricing, unmet demands (to maintain current crop yields) and crop yield changes under deficit irrigation were determined (see Figure 3). 


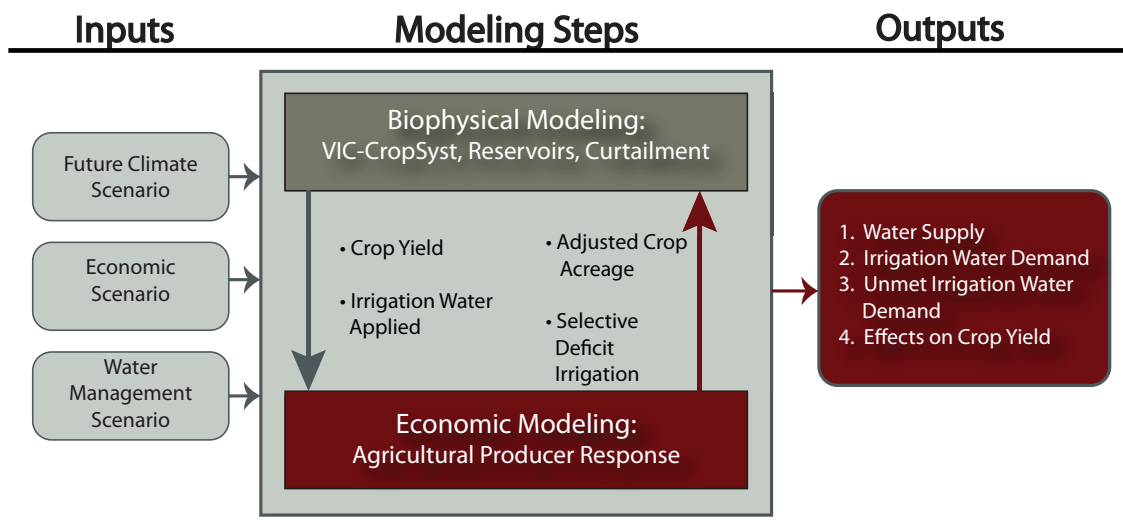

Figure 3: Integration of biophysical (surface water supply, crop dynamics and climate) with economic and policy (human decision-making) modeling.

\section{Results and discussion}

Using precipitation and temperature estimates from five global climate model scenarios, the integrated VIC-CropSyst model predicted runoff quantities throughout the CRB. Results indicated an average annual increase in supply of approximately $3.0 \%$ by 2030 compared to the historical $1977-2006$ supplies. However, the timing of runoff events shifted water away from summer months when demands are highest. Unregulated surface water supply at Bonneville was predicted to decrease an average of $14.3 \%$ between June and October and increase an average of $17.5 \%$ between November and May. Figure 4 illustrates average annual changes in streamflows entering the state of Washington.

VIC-CropSyst model outputs were linked to reservoir and water use curtailment models to evaluate how changing water supplies might impact future reservoir storages and releases, irrigation application amounts, crop yields, and the frequency that some groups of water users might be interrupted. Reservoir modeling with ColSim captured operations of the major storage dams on the Columbia and Snake Rivers. Additionally, the five major Yakima Basin reservoirs and Lake Chelan were modeled. Dam management operations considered power generation, flood control, instream flow targets, water storage, and stream flow regulation using historic rule curves.

Agriculture is a prominent driver of eastern Washington's economy and because crop watering represents the majority of consumptive water use in the CRB, the VIC-CropSyst modeling effort focused on the impacts of climate change on future irrigation demands. To properly simulate surface water supply and demand, the combined model needed accurate land use information for the entire CRB, including upstream areas in other states and Canada. To capture the diversity of agriculture across Washington, nearly 40 groups of field and pasture crops, tree fruit, and other perennials were simulated. Comparisons between 


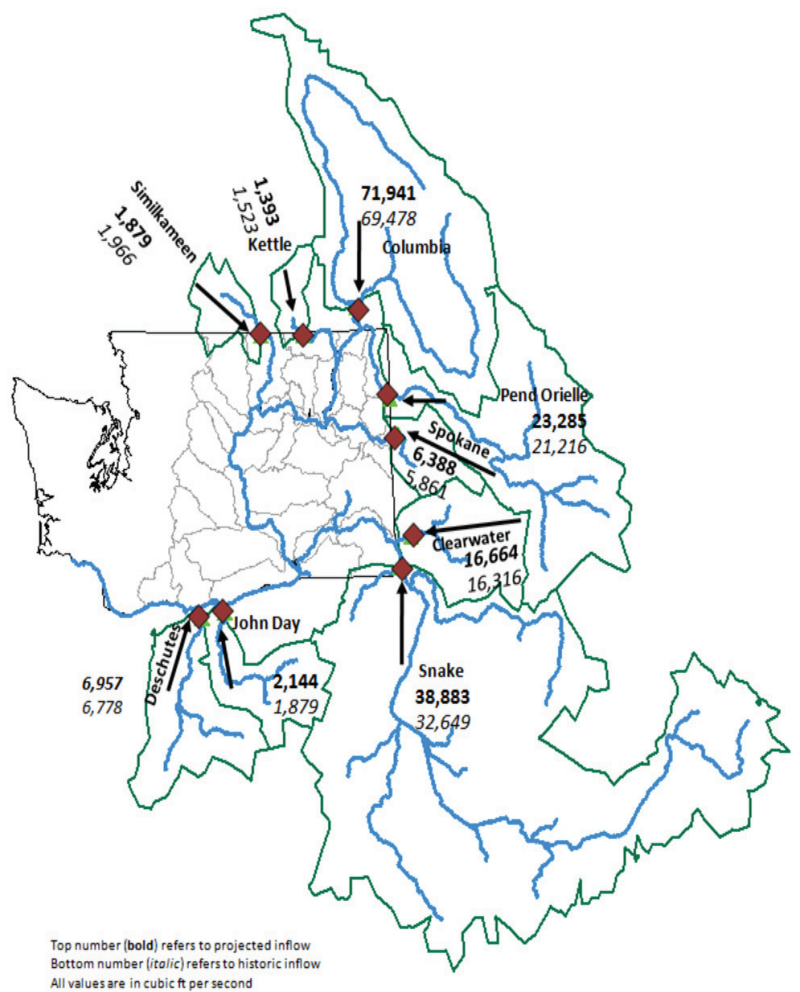

Figure 4: Surface water flows for major tributaries entering Washington State. Top numbers (bold) are the 2030 forecasted water supplies for average flow conditions using the middle climate change scenario, while the bottom number (italic) refers to historical (1977-2006) water supplies. All values are in $\mathrm{ft}^{3} / \mathrm{s}$.

historic (1977-2006) and future (2030) agricultural water demands were made at watershed and WRIA scales. Table 1 summarizes the results.

Forecast results indicate an overall $2.25 \%$ increase in crop water requirements (141,000 acre-feet) will be needed across the Washington portion of the CRB in order to maintain full irrigation of existing crops. Changes in WRIA demands are variable between watersheds (e.g., $0.03 \%$ in Walla Walla versus $7.0 \%$ in Okanogan) depending on location, cropping pattern, precipitation, soil, temperature, and other related factors (See representative table results). Without concerted efforts aimed at conservation and technological innovation, even more water will be required to grow the agricultural economy and meet the nutritional requirements of an expanding global population. Figure 5 illustrates the projected supplies along with Washington's current instream flow standards and federal biological opinion (BiOp) flow target. 
Table 1: $\quad$ Estimation of the average historical (1977-2006) and forecast 2030 WRIA-level irrigation demand.

\begin{tabular}{|c|l|r|r|}
\hline \multirow{2}{*}{$\begin{array}{c}\text { WRIA } \\
\text { Number }\end{array}$} & \multirow{2}{*}{ WRIA Name } & \multicolumn{2}{|c|}{$\begin{array}{c}\text { Total modeled WRIA-level } \\
\text { irrigation demand } \\
(\mathrm{ac}-\mathrm{ft} / \text { year) }\end{array}$} \\
\hline & & Historic & \multicolumn{1}{c|}{2030} \\
\hline 32 & Walla Walla & 209,049 & 208,996 \\
\hline 37 & Lower Yakima & $1,435,031$ & $1,476,659$ \\
\hline 38 & Naches & 94,821 & 105,019 \\
\hline 39 & Upper Yakima & 429,379 & 466,141 \\
\hline 45 & Wenatchee & 34,281 & 36,472 \\
\hline 49 & Okanogan & 102,845 & 110,050 \\
\hline 54 & Lower Spokane & 16,522 & 16,360 \\
\hline 55 & Little Spokane & 4,449 & 4,629 \\
\hline 56 & Hangman & 1,295 & 1,416 \\
\hline 57 & Middle Spokane & 371 & 404 \\
\hline Entire CRB Total within WA & $6,320,598$ & $6,461,645$ \\
\hline a 1 ac-ft $=1,233.5$ m $^{3}$ & &
\end{tabular}

Economic drivers will play an important role in future water demands. The average gross revenue for irrigated CRB land within Washington was estimated to be $\$ 3,500 /$ acre/year. This estimate is extremely variable depending on location, crop type, and commodity price. Economic projections of crop prices due to domestic and international trade were conducted to evaluate potential impacts on long-term water demands as some shifts in crop selection toward more water-efficient crops (e.g., wine grapes) is expected. Changes in agricultural demand due to these future cropping patterns were modeled using historical (1977-2006) and 2030 climate data with irrigation water, municipal, and instream flow demands projected for average flow conditions under a moderate climate change scenario.

Forecasted 2030 water demands for low, medium, and high economic growth scenarios were completed at the WRIA level. An example from the Walla Walla WRIA is shown in Figure 6. Ground water (GW, brown) and surface water (SW, dark green) irrigation demands are shown at the "top of crop" and include water that will actually be used by plants, as well as on-field losses based on WSDA-specified irrigation type. Conveyance losses (light green) are estimated separately. Instream flows (blue) for both the historical and 2030 forecast are shown using adopted state instream flows or federal flow targets. When more than one instream flow exists at the sub-watershed level for a given month, the largest value (generally the most downstream) was used to express instream flows at the WRIA level.

Without the additional 141,000 acre-ft of supply, existing junior water right holders will be forced to reduce diversions (curtailment) during summer lowflow periods resulting in lower crop yields (deficit irrigation). The economic 


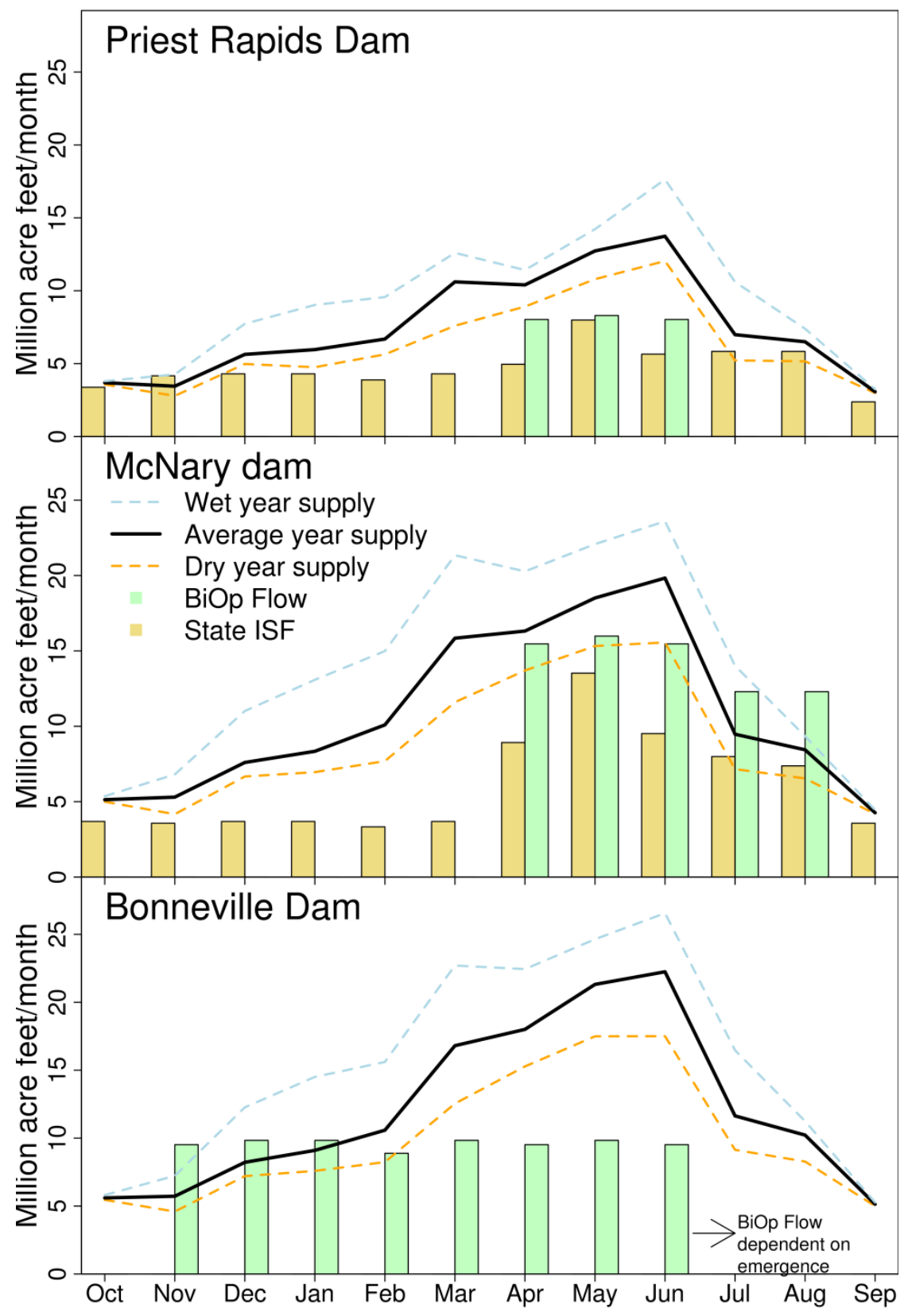

Figure 5: Forecast 2030 surface water sypplies at Bonneville, McNary and Priest Rabids dams for low $\left(20^{\text {th }}\right.$ percentile $)$, average, and high $\left(80^{\text {th }}\right.$ percentile) flow conditions. 


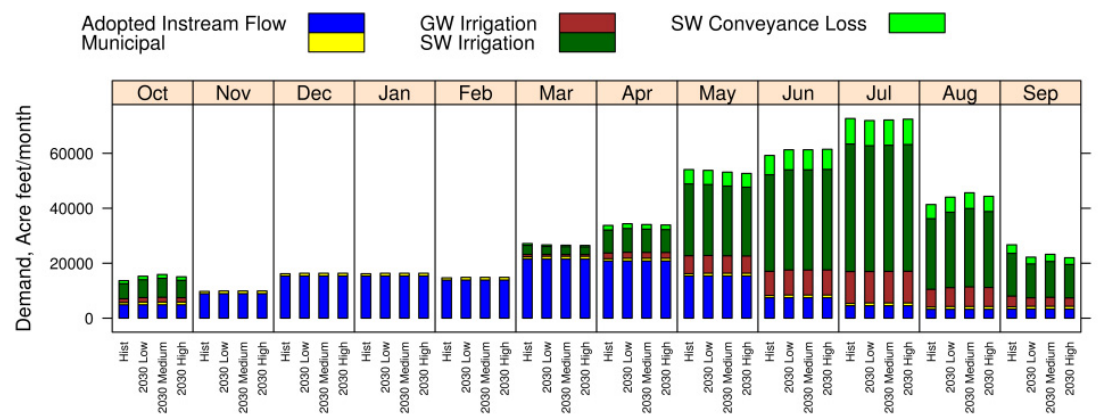

Figure 6: Typical model of historical (1977-2006) and 2030 irrigation, municipal, and instream flow demands under average flow and average climate change conditions.

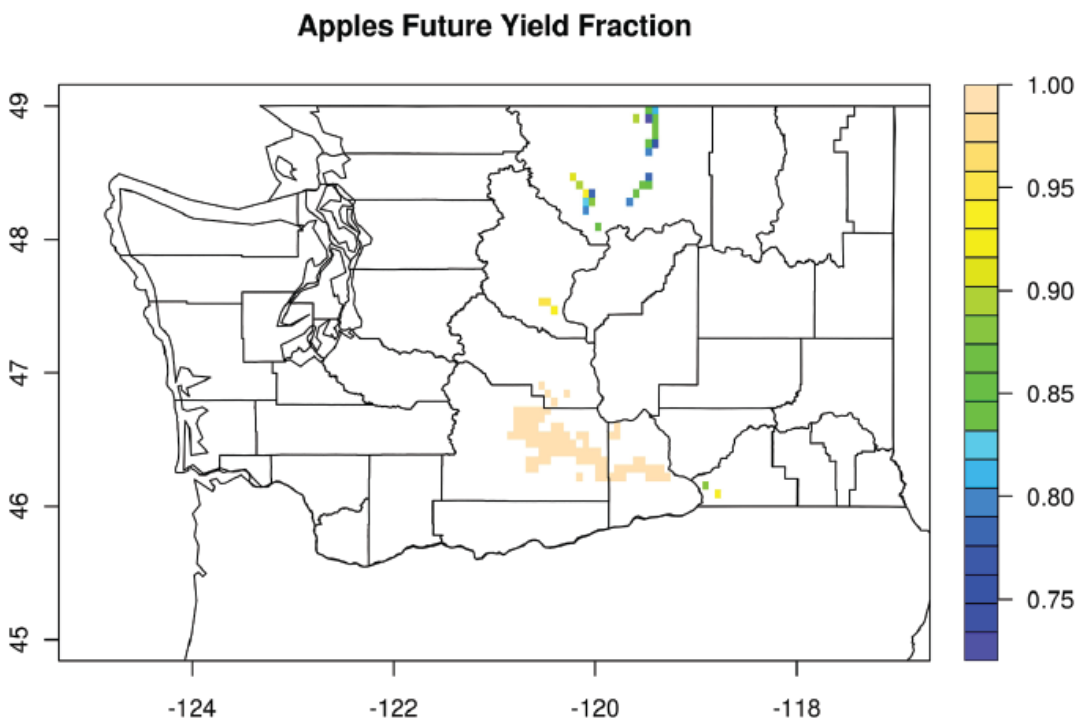

Figure 7: Climate change implications on crop yields.

impacts of curtailments vary considerably by WRIA, crop, hydrologic severity, and growing season cycle. Using apples as an example, the deficit irrigation scenario (see Figure 7) shows yields reduced to approximately $75 \%$ of normal in the Okanagan watershed versus a near $95 \%$ of normal in the Yakima watershed. Consequently it is difficult to place an economic value on the additional water demand. Our rough estimates place the loss between $\$ 68-\$ 159$ million/year assuming no changes in efficiency and little adaptation of cropping practices. 
Not all crop yields decrease as a function of climate change. Non-irrigated winter wheat yields are expected to increase significantly as a result of modest winters and seasonal rainfall increases across the primary growing regions. Figure 8 illustrates changes in yield for non-irrigated winter wheat.

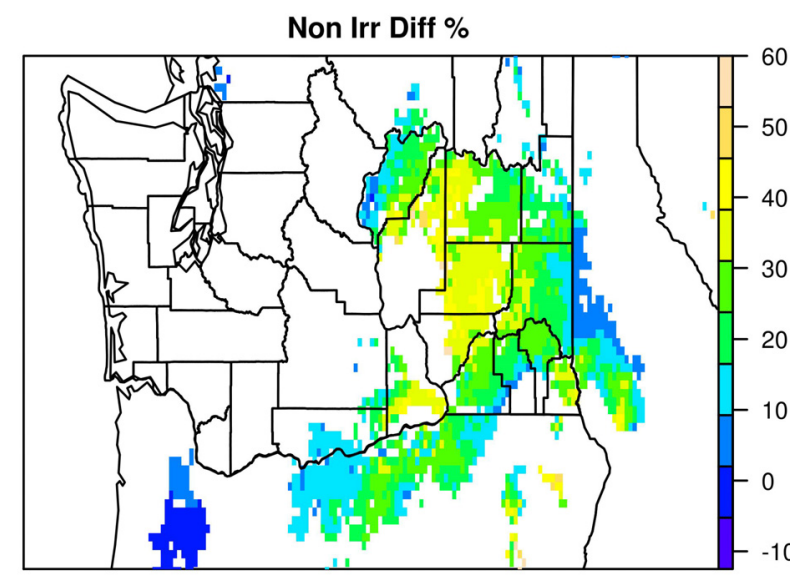

Figure 8: $\quad$ Percent difference in non-irrigated winter wheat yields.

\section{Conclusions}

This study focused on the 2030 impacts of climate change, population growth, agricultural prices, and instream flows on water supplies and demand in the Columbia River basin. It represents the most comprehensive study of future supply and demand ever produced in the state of Washington. Results indicate nearly 110,000 acre-feet of additional diversions will be needed for municipal growth and more than 140,000 acre-feet will be needed to maintain existing irrigation practices excluding the groundwater crisis facing the Odessa area. Likewise, water for ecosystem protecting is needed in many Washington streams and rivers.

The physical availability of water will become increasingly important during summer low-flow periods with average flow decreases of over $14 \%$ in many places. The best long-term solution may very well involve a combination of water conservation and new storage. More work is needed to evaluate the full implications of conservation measures in terms of return flows and economic impacts compared to storage options such as aquifer storage and recovery. Nevertheless, it is abundantly clear that agriculture, water, salmon and energy are essential to Washington and innovative solutions must be sought as a means of insuring our future. 